University of Nebraska - Lincoln

DigitalCommons@University of Nebraska - Lincoln

Textile Society of America Symposium

Proceedings

2020

Casting a Wide Net: The Value of Collaboration and Outreach with

Source Communities in the Analysis of Historic Native American

Fishing Nets

Annabelle Fichtner Camp

The Lenape Tribe of Delaware

Follow this and additional works at: https://digitalcommons.unl.edu/tsaconf

Digitadrt of the Art and Materials Conservation Commons, Art Practice Commons, Fashion Design

Commens, Fiber, Textile, and Weaving Arts Commons, Fine Arts Commons, and the Museum Studies

detwerkns

Logo

This Article is brought to you for free and open access by the Textile Society of America at

DigitalCommons@University of Nebraska - Lincoln. It has been accepted for inclusion in Textile Society of America

Symposium Proceedings by an authorized administrator of DigitalCommons@University of Nebraska - Lincoln. 


\title{
Casting a Wide Net: The Value of Collaboration and Outreach with Source Communities in the Analysis of Historic Native American Fishing Nets
}

\author{
Annabelle Fichtner Camp in Collaboration with the Lenape Tribe of Delaware
}

annabellefcamp@gmail.com

\section{Introduction}

Among Native groups of the Mid-Atlantic, historic fishing nets represent both a lost craft and a reminder of how their ancestors once sustained themselves along the Atlantic coast and the shores of the Delaware and Chesapeake Bays. For the Lenape Tribe of Delaware, the work of the last community netmaker, Clem Carney, offers a specific point of pride. Carney's nets and tools were collected in the early 1900 s by the cultural anthropologist C.A. Weslager, who illustrated them in his publication Delaware's Forgotten Folk. ${ }^{1}$ While two of these objects can be found within the collections of the National Museum of the American Indian at the Smithsonian Institution (NMAI), most cannot be found or have not been preserved. This loss highlights years of misidentification and neglect of the Lenape Tribe of Delaware and their cultural heritage. It also points at a need to study, understand, and preserve this once crucial technology.

Sparked by the Tribe's desire to find and study Carney's nets, an 18-month-long project was completed in collaboration with the Lenape Tribe of Delaware. Running from the winter of 2018 to the spring of 2019, this project sought to study all extant examples of historic Mid-Atlantic Native American fishing nets within museum collections. The goals of the study were to create an inventory of the nets and associated materials found and engage the community in the examination and preservation of their material culture through sustained outreach events.

This article will provide an overview of the project, but its aim is not to discuss the findings of the net analyses. Instead, this article aims to examine the precedence and impetus for collaborative research with a source community and demonstrate the value of collaboration and associated outreach in object-based decolonization and Indigenous knowledge reclamation.

\section{The Lenape Tribe of Delaware and the Nets of Clem Carney}

The Lenape Tribe is one of two state-recognized tribes in Delaware. Although they only gained this recognition in 2016, they have inhabited the Delmarva Peninsula and larger ancestral region of Lenapehoking for millennia. However, their presence had been all but forgotten by the nonNative community in the aftermath of colonization.

Prior to the arrival of European colonizers, the Lenape lived in semi-permanent communities along the Delaware and Chesapeake Bays and their tributaries in what is now New Jersey, Delaware, eastern Pennsylvania, southern New York, and western Connecticut. While Europeans

\footnotetext{
${ }^{1}$ C.A. Weslager, Delaware's Forgotten Folk : The Story of the Moors \& Nanticokes (Philadelphia: University of Pennsylvania Press, 2006 [1943]).
} 
are recorded to have visited Lenapehoking as early as $1524,{ }^{2}$ colonization of the region did not begin until $1609 .{ }^{3}$ The region was subsequently controlled by the Swedes and Dutch before finally becoming part of the English colonies. While peoples living along the east coast of modern-day North America are believed to have utilized the local environment of lakes, rivers, and coastlines since approximately $8000 \mathrm{BCE},{ }^{4}$ no written record prior to colonization exists. Numerous colonists and missionaries documented and even published their first-hand accounts and observations of the Lenape. However, there is no account of their daily lives or "material, spiritual, and social conditions." The majority of existing accounts are biased and inaccurate.

As one of the first Indigenous groups along the Atlantic coast to interact with Europeans, the Lenape have been severely affected by colonization for centuries. Since the arrival of Europeans, the Lenape either acculturated, converting to Christianity and marrying white colonists, or moved. ${ }^{6}$ In a series of mass migrations between 1754 and 1868, the majority of the Lenape peoples were forced to move from their ancestral homelands. A large group went to Ontario, where a Munsee-Delaware ${ }^{7}$ Nation is still located. Others were forced west, first into western Pennsylvania, then Ohio, Indiana, Missouri, Kansas, and ultimately Oklahoma, where the federally recognized Delaware Tribe is based. ${ }^{8}$ These migrations are documented in C.A. Weslager's work The Delaware Indian Westward Migration. In it, Weslager published data acquired from the Delaware Tribal Business Committee on where the 4,708 "Delaware Indians" of voting age lived in $1977 .{ }^{9}$ The list showed "Delaware" people living in 45 US states and Washington, D.C., but not the state of Delaware. This belief by the larger non-Native community that Lenape people no longer lived in Lenapehoking was due in large part to misidentification by $20^{\text {th }}$-century anthropologists.

Beginning in 1912, the Lenape Tribe of Delaware became the subject of study by leading University of Pennsylvania anthropologist, Frank Speck and his student C.A. Weslager. These two men studied the modern-day Lenape's ancestors, including Clem Carney, and collected their objects and stories. Weslager, who noted the group's resemblance to their Indigenous neighbors the Nanticoke, failed to recognize the community as Lenape. ${ }^{10}$ Instead he referred to the group as "Delaware's Forgotten Folk" or "Moors," peoples believed to be of Spanish descent. ${ }^{11}$ Even when, in 1948, the Smithsonian Institution did refer to the Tribe as "a surviving Indian group of the eastern U.S.,"12 it still failed to identify them as Lenape.

\footnotetext{
${ }^{2}$ Kraft, Herbert C. The Lenape Indian : A Symposium. South Orange, N.J.: Archaeological Research Center, Seton Hall University, 1984, 22.

3 Ibid., 23.

${ }^{4}$ Merwyn Garbarino and Robert F Sasso, Native American Heritage (Prospect Heights, Ill.: Waveland Press, 1996), 29.

${ }^{5}$ Herbert C. Kraft, The Lenape-Delaware Indian Heritage (Place of publication not identified: Lenape Books, 2001), 24.

${ }^{6}$ Ibid.

${ }^{7}$ Lenape peoples are also referred to as Delaware. This name originates from the Lord De La Warr for whom the Bay, state, and its original inhabitants were named by European colonizers.

${ }^{8}$ C.A. Weslager, The Delaware Indian Westward Migration (Wallingford, Pa.: Middle Atlantic Press, 1978 ), 12.

${ }^{9}$ Ibid., 228.

${ }^{10}$ Ibid.

11 Ibid., 25

1229 DE Code $§ 106$ (2016). JUSTIA Law, Accessed June 30, 2020,

https://law.justia.com/codes/delaware/2016/title-29/chapter-1/section-106/.
} 
Today the Lenape Tribal government, under the leadership of Chief Dennis Coker, is located in Cheswold, DE. Although the Tribe "has an unbroken history of hundreds of years of settlement and continued residency in the vicinity of Cheswold" and "can date their ancestral ties as far back as the early 1700s," "13 they battled for 26 years to receive state recognition, and are still battling to reclaim the knowledge erased by colonizers and the systemic oppression that has followed.

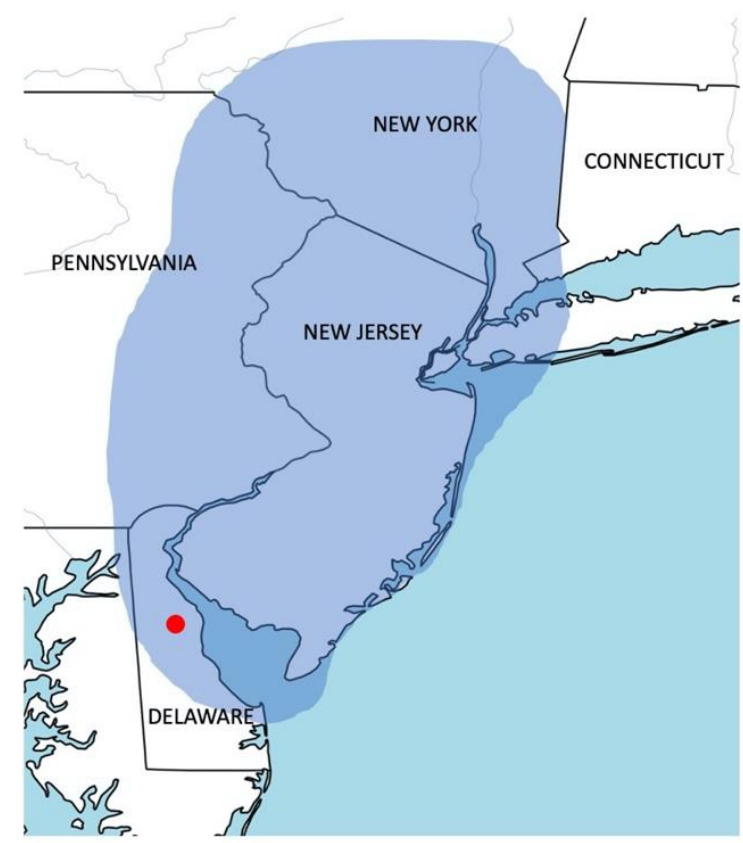

Map with ancestral region of Lenapehoking highlighted in blue. Cheswold, DE is marked with a red circle.

Unlike other Delaware groups who have been able to remain as large cohesive groups, the Lenape Tribe of Delaware has struggled to retain a core identity in the eyes of the state and federal governments. Since 1609, their traditional lifeways have been altered by many factors, including displacement, intermarriage, and acculturation, and unfortunately the Tribe deems many of their ancestral practices to be lost. As part of their prolonged battle to reclaim their identity, the Lenape Tribe of Delaware has worked to revitalize the practices that would have sustained their ancestors in Lenapehoking, including the once-crucial act of net-making.

\section{Project Impetus and Overview}

The author approached Lenape leadership in 2018 to discuss the possibility of a collaborative project that would serve the research interests of the Lenape community. The topic of netmaking, inspired by the works of Clem Carney, was one of many options the Tribe put forth. Clem Carney was born in Cheswold, DE shortly after the American Civil War, and his descendants are active in the community today. As of 1943, Carney was the only netmaker remaining in the Lenape community. Unfortunately, none of his nets survive within the community, and few people who knew Clem Carney personally are living today.

\footnotetext{
1329 DE Code $§ 106$ (2016). JUSTIA Law, Accessed June 30, 2020, https://law.justia.com/codes/delaware/2016/title-29/chapter-1/section-106/.
} 


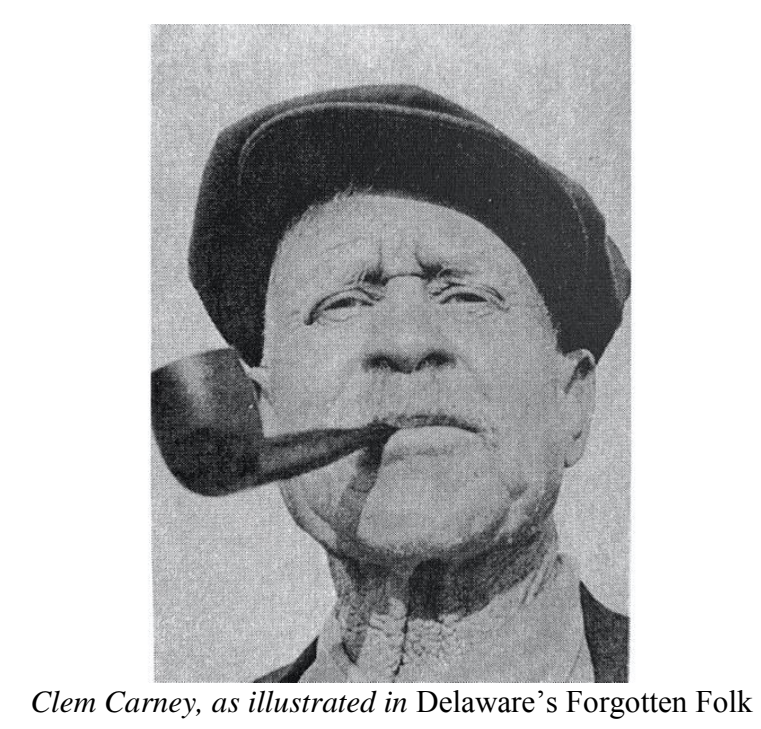

Tribal member Patsy Cline knows that Clem taught her grandfather how to tie nets and remembers Carney tying nets in a shed at the end of his driveway. ${ }^{14}$ Yet no one else within her family learned the craft, and no other Carney students have been identified. The Tribe was therefore most familiar with his work through illustrations included in C.A. Weslager's book Delaware's Forgotten Folk. During his many visits to Cheswold, Weslager collected examples of both Carney's tools and nets, including two gauges, two shuttles, a net float, and a dip net. These objects were believed to have been donated to the Heye Collection, which was transferred to the Smithsonian Institution in 1989 and became the founding collection of the National Museum of the American Indian. ${ }^{15}$ Aware of these illustrations and the possible location at the Smithsonian, the Tribe hoped that extant nets made by Carney could be found and studied. Unfortunately, only two of the objects documented by Weslager - a shuttle and a float - could be located in the NMAI collection, and no evidence of Carney's work can be found within other North American collections.

\footnotetext{
${ }^{14}$ Patsy Cline, Personal Communication, 2018.

15 "National Museum of the American Indian. History of the Collections," Smithsonian Institution, Accessed June 20, 2020, https://americanindian.si.edu/explore/collections/history.
} 


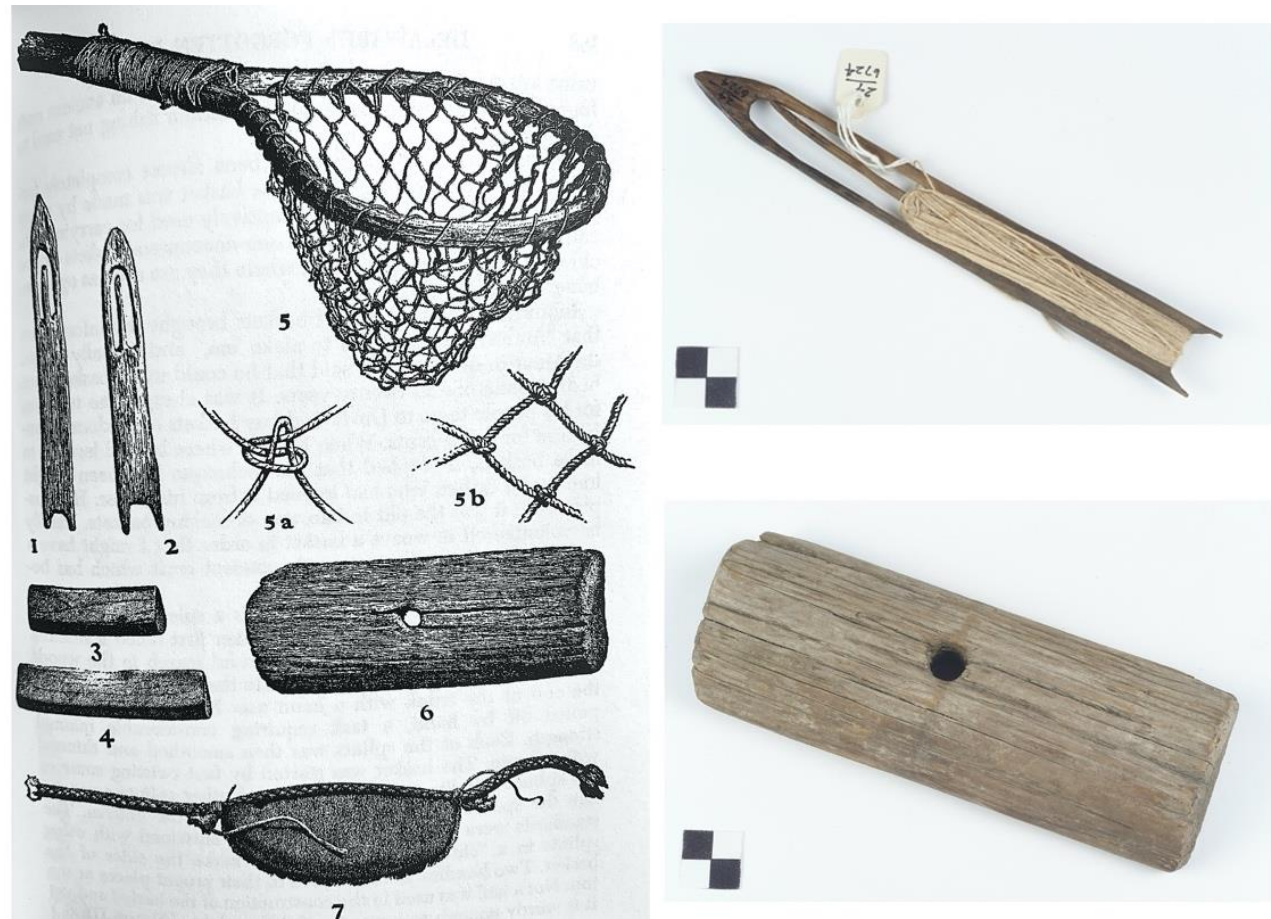

Carney's nets and tools as illustrated in Delaware's Forgotten Folk and a shuttle (NMAI 246724.000) and pine float (NMAI 246726.000) believed to be those illustrated and found in the collection of the National Museum of the American Indian, Smithsonian Institution

Despite this loss of Carney's nets, the project moved forward with an expanded scope: to study all extant examples of Mid-Atlantic fishing nets. The largest influence on variation among fishing nets is their intended use, and Native Mid-Atlantic peoples have fished for similar, if not the same fish species in analogous environments. For these reasons, parallels can be drawn between nets from differing tribes and generations. In total, 20 historic net or net fragments and 39 net-making tools representing six Mid-Atlantic tribes were examined at both NMAI and the American Museum of Natural History (AMNH). Technical details related to construction (net type, mesh size, knotting and construction method), material (cordage material, spin, and ply) and cultural context (presence of repairs and preservatives) were recorded systematically on data sheets that are now included with each object's museum record. This study reinforced the concept that similar if not the same construction methods were used by people of differing tribes in the same geographic region. It also shed light on the use of historic preservatives and native cordage fiber plants, ${ }^{16}$ which is of specific interest to the Lenape Tribe and is therefore important for future research. Additionally, to facilitate future research, an inventory of over 290 Native Mid-Atlantic nets and associated materials from museums throughout North America was compiled.

During the course of the technical study, the Tribe was consulted and updated frequently. A series of outreach events allowed this work to not simply be a study of nets, but to achieve a higher goal of object-based decolonization and knowledge reclamation.

\footnotetext{
${ }^{16}$ Eight handmade cordage examples estimated to include dogbane, slippery elm, and either milkweed or nettle were found among the nets studied.
} 


\section{Decolonization of Museums and Indigenous Knowledge Reclamation}

It is widely accepted that modern museums, which originated in the curiosity cabinets of Renaissance Europe and were established in the late $19^{\text {th }}$ century, are rooted in white colonial power and have perpetuated a narrative of white supremacy over Indigenous peoples. ${ }^{17,18}$ This has resulted in Euro-centric stories and interpretations of all objects, whether or not they are of European origin. In recent years, this concept has been challenged by cries for not only repatriation of objects, but also the larger "decolonization" of museums, which Linda Tuhiwai Smith (Ngāti Awa and Ngāti Porou iwi) defines as "a long-term process involving the bureaucratic, cultural, linguistic, and psychological divesting of colonial power."19 This involves the acknowledgement of a history of discrimination and the associated grief, as well as a commitment to respect and prioritize the knowledge and perspectives of oppressed peoples. ${ }^{20}$ This process should affect all aspects of a museum, including its hiring, acquisitions, curation, conservation, and research.

In her work, Museum Pieces: toward the indigenization of Canadian museums, Ruth B. Phillips analyzes efforts, including digital repatriation and research projects, that a number of Canadian museums have undertaken to confront their own colonial histories and uplift Indigenous voices. ${ }^{21}$ The Royal Ontario Museum, which is actively working to infuse Indigenous knowledge and perspectives into their public programming, has made particularly notable efforts in this respect, as outlined by the Manager of Learning, Wendy $\mathrm{Ng}$, and Indigenous Outreach \& Learning Coordinator J'net AyAyQwaYakSheelth (Ahousaht), in the article "Decolonize and Indigenize: A Reflective Dialogue." ${ }^{\prime 2}$ Leaders in decolonizing efforts in America include NMAI, the Walker Art Center, ${ }^{23}$ and the San Diego Museum of Man, which has started a series of decolonization initiatives $^{24}$ to address their self-acknowledged colonial and oppressive past. This movement

\footnotetext{
${ }^{17}$ Wendy Ng and J'net AyAyQwaYakSheelth, "Decolonize and Indigenize: A Reflective Dialogue," NAEA Museum Education, June 12, 2018, Accessed June 12, 2020. https://medium.com/viewfinder-reflecting-on-museumeducation/decolonize-and-indigenize-a-reflective-dialogue-3de78fa76442.

${ }^{18}$ Ruth B. Phillips, Museum Pieces : Toward the Indigenization of Canadian Museums (Montreal: McGill-Queen's University Press, 2011), 228.

${ }^{19}$ Linda Tuhiwai Smith, Decolonizing Methodologies : Research and Indigenous Peoples (London: Zed Books, 1999), 98.

${ }^{20}$ Wendy Ng and J'net AyAyQwaYakSheelth, "Decolonize and Indigenize: A Reflective Dialogue," NAEA Museum Education, June 12, 2018, Accessed June 12, 2020. https://medium.com/viewfinder-reflecting-on-museumeducation/decolonize-and-indigenize-a-reflective-dialogue-3de78fa76442.

${ }^{21}$ Ruth B. Phillips, Museum Pieces : Toward the Indigenization of Canadian Museums (Montreal: McGill-Queen's University Press, 2011).

${ }^{22}$ Wendy Ng and J'net AyAyQwaYakSheelth, "Decolonize and Indigenize: A Reflective Dialogue," NAEA Museum Education, June 12, 2018, Accessed June 12, 2020. https://medium.com/viewfinder-reflecting-on-museumeducation/decolonize-and-indigenize-a-reflective-dialogue-3de78fa76442.

23 "Decolonize This Place," Walker Art Center, 2016, Accessed June 12, 2020, https://walkerart.org/magazine/authors/decolonize-this-place-606.

24 “Decolonizing Initiatives," San Diego Museum of Man, Accessed June 12, 2020, https://www.museumofman.org/decolonizing-initiatives/.
} 
goes beyond North America, with notable examples of decolonizing efforts found in Brazil, ${ }^{25}$ Australia, ${ }^{26}$ and New Zealand. ${ }^{27}$

A large component of the decolonization effort is object-based research and associated knowledge reclamation. ${ }^{28,29}$ As written records of Indigenous lifeways, particularly precolonial, are rarely available, objects can act as valuable resources and voices. They can be essential in regaining knowledge of practices that were forced out of use by colonization. Through their analysis, rituals, utilization of resources, technology, and trade can be better understood. A key factor in successful object-based research for the purpose of decolonization and knowledge reclamation is allowing the source community to decide what objects they deem valuable to study. In many instances, objects of everyday use, such as the fishing nets examined in this project, were considered inconsequential by white curators or collectors, resulting in these collections not being studied and a subsequent loss of understanding. None of Clem Carney's nets can be found, suggesting these objects were not considered valuable for accession, documentation, or preservation. However, their significance cannot be overstated.

For the Lenape Tribe of Delaware, fishing nets are a connection to their precolonial ancestors, representing a means of survival prior to and in the wake of colonization. The nets and the examples of natural fiber cordage that were examined also provide connections to the ecology of Lenapehoking. They harken to the waterways that the Lenape Tribe call their life and are actively fighting to protect, as well as the native plants that were at one point used for both cordage and medicine. Thus, even though Carney's nets could not be found, Native Mid-Atlantic fishing nets were deemed essential objects of study by the Tribe. As P. Pitiki Ntuli notes, "any knowledge reclamation project cannot reclaim a past in its pristine form." ${ }^{30}$ Not all of the material culture that colonization and subsequent oppression destroyed can be recovered, but much of the knowledge it represents can be. As the Lenape continue to fight for recognition from their nonNative community and government, these nets can be used to draw powerful connections to the people and places of the Lenape past, present, and future.

\section{The Role of the Conservator}

This specific project was conducted by a student of art conservation, and while actual conservation treatment of objects was not conducted, common examination techniques employed in conservation were utilized, and a number of the professionals who advised on the project are

\footnotetext{
${ }^{25}$ B.B. Suares and L. Guedes, "Four Waurá masks in the Indian Museum: a decolonial way to conservation practice and theory," What is the essence of conservation, ICOMOF (2014): 32-38.

${ }^{26}$ Lainie Schultz, "Maintaining Aboriginal Engagement in Australian Museums: Two Models of Inclusion," Museum Management and Curatorship 29, no. 5 (2014): 412-28.

${ }^{27}$ Puawai Cairns, "Decolonise or Indigenise: Moving Towards Sovereign Spaces and the Māorification of New Zealand Museology," Museum of New Zealand, Te Papa Tongarewa, February 10, 2020. Accessed June 10, 2020, https://blog.tepapa.govt.nz/2020/02/10/decolonise-or-indigenise-moving-towards-sovereign-spaces-and-themaorification-of-new-zealand-museology/.

${ }^{28}$ Elizabeth, Harney and Ruth B. Phillips, Mapping Modernisms : Art, Indigeneity, Colonialism. Objects/Histories: Critical Perspectives on Art, Material Culture, and Representation (Durham: Duke University Press, 2018).

${ }^{29}$ Heather L Igloliorte, Rooms Corporation of Newfoundland and Labrador, and Rooms Provincial Art Gallery (N.L.), Sakkijâjuk : Art and Craft from Nunatsiavut (Fredericton, NB, Canada: Goose Lane Editions, 2017).

${ }^{30}$ P.P. Ntuli, "Indigenous Knowledge Systems and the African Renaissance," In Indigenous Knowledge and the Integration of Knowledge Systems : Towards a Philosophy of Articulation, 53-66, (Place of publication not identified: New Africa Books, 2002).
} 
practicing textile conservators. Thus, the role conservators play in Indigenous knowledge reclamation and object-based decolonization was a constant consideration.

With the opportunity that art conservators have to examine, handle, and preserve material culture, comes a unique responsibility. The American Institute for Conservation states in their Code of the Ethics that "conservators' actions must be governed by an informed respect for the cultural property, its unique character and significance, and the people or person who created it." Additionally, it states that conservators must seek to "recognize the specialized knowledge of others." 31 Thus, it seems imperative that conservators preserve whenever possible not only the tangible aspects of an object by attempting to slow its physical degradation, but also the intangible knowledge it conveys: how it was made, how it was used, and what it means within a specific culture or community. To not gather this information from a source community, and to not involve a community with the preservation of their own material culture, poses as great a risk to the object's meaning as allowing it to physically degrade. Additionally, conservators have a responsibility to share their knowledge, which can provide insights on an object's manufacture, material, and long-term preservation, with its stakeholders through open communication and outreach.

\section{Outreach}

Outreach was a constant component of this project, considered equally important to its success as the research itself. This included outreach activities within the Tribal community, as well as outreach targeted toward the general public. Chief Dennis Coker felt it was important to make opportunities available to the public so as to strengthen the Tribe's visibility within the state. These various outreach events included a Tribal delegation visit to the National Museum of the American Indian Cultural Resource Center (CRC), public talks, and net-making workshops.

\section{Tribal Delegation to the National Museum of the American Indian Cultural Resources Center}

The majority of the nets and tools studied as part of this research are housed at the CRC in Suitland, MD. In August 2018, following the examination of these objects, a Lenape Delegation came to the Center to see the materials. The delegation consisted of ten people, including Chief Coker and four of Carney's direct descendants, and was accompanied by Delaware Public Media correspondent Sophia Schmidt.

Prior to viewing the collections, the delegation discussed their goals for the day, prayed, and performed a traditional sage burning. They then viewed the nets and associated tools that had been pulled, and they were reunited with the two tools identified to have been made and used by Clem Carney: a pine float and shuttle with cordage. For Melody Cline and her three children, direct descendants of Clem Carney, seeing the hand-carved tools of Carney, which bore the signs of his use and offered a previously lost window into his renowned practice, was incredibly powerful.

The visit, which lasted all day, enabled the Tribal members to speak with the Center's conservators, archivists, and collection managers and learn about the opportunities the Center

\footnotetext{
31 "Core Documents: American Institute for Conservation of Historic and Artistic Works," AIC, 2015, Accessed June 25, 2020, https://www.culturalheritage.org/docs/default-source/administration/governance/code-of-ethics-andguidelines-for-practice.pdf?sfvrsn=ca344aed_21.
} 
offers to tribal communities. The entire delegation was grateful to understand what material knowledge could be gleaned from the pieces, and they provided their own interpretations and stories associated with Carney's tools, as well as the other nets being viewed. Throughout the day, delegation members told stories of fishing with similar nets or in the same waters that Carney once fished. They offered insight on what fish would have been caught during different seasons and in estuaries of the region. They were also excited to see the examples of handmade cordage and learn about ongoing research into cordage fibers taking place at the Center.

Repeatedly, members of the delegation noted the significance these objects have in understanding their ongoing and changing relationship with their Native environment. During the visit, delegate Ruth Ann Purchase spoke of the Tribe's strong connection to the water that the nets represent - referring to the water as "their lives." The variety of nets observed that day demonstrated the diverse aquatic life within the Lenape environment, as well as the skill of the netmakers that unfortunately is no longer present within the community.

During the visit, Sophia Schmidt captured the wonderful moment when Nora Frankel, Andrew W. Mellon Fellow in Textile Conservation, taught seven-year-old Charlotte Cline, daughter of Melody and Carney descendant, how to make dogbane cordage similar to that seen on two of the nets. In that moment, it became clear that even though no one can make nets within the Lenape community today, the knowledge that they contain is very much alive. While the skill of netmaking is no longer necessary, these objects have a unique ability to reconnect the community to their environment and their ancestors.
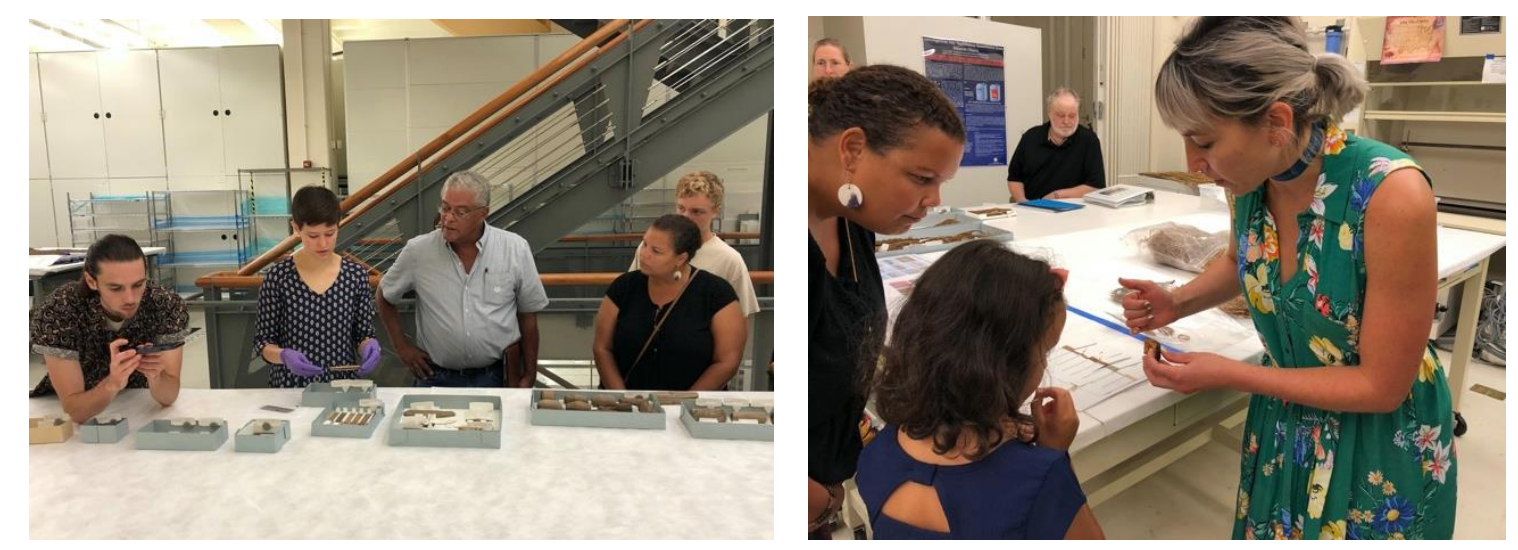

Left: Members of the delegation and the author discuss net-making shuttle and float; Right: Andrew W. Mellon Fellow in Textile Conservation Nora Frankel demonstrates cordage making to Melody and Charlotte Cline (Images courtesy of Sophia Schmidt and taken at NMAI CRC).

\section{Public Talks}

Following the research visits and delegation, preliminary findings were shared with the larger Lenape community. This allowed for the members of the delegation to reflect on their experience with others and for the entire community to be kept abreast of the research's progress. Two public lectures were given by the author in Cheswold and Newark, DE. The lecture was scheduled twice so that Lenape from both Cheswold and northern Delaware, as well as scholars from throughout the state, could learn about the research. Tribal community members and elders, University of Delaware professors, and employees from the Partnership for the Delaware Estuary 
attended and engaged in valuable discussions,. Chief Coker and community members provided useful feedback and suggestions on how to continue the research and the best ways to engage a larger audience.

As word of the research spread throughout the state of Delaware, in large part due to Sophia Schmidt's article about the delegation trip, invitations to present the project in a variety of other settings were received. ${ }^{32}$ A public lecture was presented as part of a Delaware State Park Lecture Series at Seashore State Park, in Bethany Beach, Delaware, and the research was shared as part of the University of Delaware Center for Historic Architecture and Design Symposium, Documenting Delaware's Historic Architecture and Heritage, on May 4, 2019. At both events, many of the attendees, who were themselves living along the waterways once fished by Lenape, confessed they were previously unaware of the Tribe's existence and left with a newfound respect for the people who have lived in the area for millennia. Additionally, this increased visibility helped to secure the support of the Biggs Museum of American Art in Dover, DE, where a series of net-making workshops were held.

\section{Net-Making Workshops}

The final component of the project's outreach was a series of hands-on net-making workshops. Chief Dennis Coker knows that few, if any, Tribal members will begin tying nets as a result of this research. However, he noted that understanding these materials is most valuable as an "exercise in reminding [Lenape] people in how resourceful they were in order to survive" and has the ability to spark a greater interest in the Tribe's material culture in general. Reconstructing an ancestral craft allows Tribal members to gain a greater understanding and appreciation for the object that was previously crucial to their sustenance. Once again, the Tribe agreed that including the non-Native public in the net-making workshops allowed for a wider acceptance and respect for Lenape culture on a state and national level. The Biggs Museum of American Art in Dover, Delaware, located approximately seven miles from Cheswold, agreed to host these workshops, which coincided with the exhibition "Rooted, Revived and Reinvented: Basketry in America." This provided an exciting opportunity to bring Native American art and technology into an American art museum. Sewell C. Biggs Curator of American Art, Ryan Grover noted that by collaborating with source communities, "it strengthens the entire community by witnessing, understanding, stopping the growth of and taking part in the healing of historic misdeeds. It broadens public awareness of what American means."

All three of the tying workshops were held in conjunction with the museum's admission-free Saturdays, so that the events were not cost-prohibitive. They were led by the author, based on the techniques observed during analysis of the historic nets, as well consultations with non-Native net-makers of the region ${ }^{33}$ and a variety of net-making workbooks. ${ }^{34,35,36}$ The first workshop was well-attended by people of all ages and both Native and non-Native community members. It

\footnotetext{
${ }^{32}$ Sophia Schmidt, "Lenape group and UD student travel to study traditional

fishing nets," Delaware Public Media, September 14, 2018, Accessed June 20, 2020,

https://www.delawarepublic.org/post/lenape-group-and-ud-student-travel-studytraditional-

fishing-nets.

${ }^{33}$ Ben Dize, Personal Communication, 2018.

${ }^{34}$ Clifford W. Ashley, The Ashley Book of Knots (Garden City, New York: Doubleday, 1944).

${ }^{35}$ Charles Holdgate, Netmaking (Emerson Books, 1972).

${ }^{36}$ Barbara Morton, Down East Netting: A History and How-to of Netmaking (London: Peasoup Publishing, 1988).
} 
included an introduction to the research followed by a hands-on workshop focused on tying flat nets. Participants received cotton cordage and plastic shuttles, as well as handouts illustrating common knots used in the net-tying process. The most enthusiastic attendee was 10 years old. He adeptly cast on a net and took materials home to complete it. His excitement was contagious during the workshop, and all Tribal members in attendance deemed the workshop a success.

The second workshop had the same structure as the first. However, the focus was on tying nets in the round. The final workshop was held in conjunction with Dover Days, a long running, free event, which brings hundreds of visitors through Downtown Dover and the Biggs Museum. A shorter hands-on activity was developed with Ryan Grover to engage visitors as they walked through the museum. It involved a quick introduction to the project and the option to tie a few meshes onto a net that continued to grow throughout the day. It was a successful method for introducing the technology and its history to the broader Dover community.

\section{Outreach Impact and Continued Research}

The scope of the project's outreach outside of the Tribal community was broadened by unanticipated media coverage. In addition to Sophia Schimdt's article, ${ }^{37}$ the research was featured on six different websites, including both state-wide and national news sources. It was also acknowledged by two professional organizations in archaeology and art conservation, as well as the Delaware State Parks Department. Information regarding the project was shared in hard copy newsletters, exhibition brochures, web articles, blog posts, and a variety of social media outlets including Twitter, Facebook, and Instagram. Additionally, the research was presented in public lectures and workshops in all three of Delaware's counties. Based on attendance at these public events and the recorded number of people reached by web-based content, it is estimated that over 7,000 people learned about this research, the Lenape Tribe of Delaware, and the value of collaborative research with source communities.

Within the Tribe, engagement was at times difficult, due in part to the presence of larger community issues. In January 2019, one of two historic Lenape churches, Immanuel Union United Methodist Church, burned to the ground, and numerous Tribal elders passed during the course of the research. Additionally, many community members were rightfully leery of nonNative scholars. As the project continued and the legitimacy and thoughtfulness of the research was proven, engagement of Tribal members steadily grew. This highlights the need for scholars to undertake collaborative research with an open mind and schedule. Patience and a respect for Tribal decision-making processes is mandatory. The goal of such research is to reclaim Indigenous knowledge, and thus the choice of what knowledge is deemed important belongs to the Indigenous community, not the scholar. The researcher's priority must be to facilitate this crucial work.

\section{Impact}

The primary goals of this project were met within its 18-month timeline. It succeeded in connecting the Lenape Tribe with large institutions, including NMAI, AMNH, and the Biggs

\footnotetext{
${ }^{37}$ Sophia Schmidt, "Lenape group and UD student travel to study traditional fishing nets," Delaware Public Media, September 14, 2018, Accessed June 20, 2020, https://www.delawarepublic.org/post/lenape-group-and-ud-student-travel-studytraditionalfishing-nets.
} 
Museum of American Art. Numerous museum professionals learned about the Lenape and the collaboration as a whole. Additionally, non-Native Delawareans learned about and gained a greater respect for the Lenape through the outreach events. Most importantly, however, this project succeeded in engaging the Lenape Tribe with the examination, preservation, and reconstruction of an ancestral practice. Through this project, many of the tangible and intangible aspects of a technology that has been so integral to the history of Mid-Atlantic Native groups collectively were preserved and made available for further study.

\section{Further Research}

Chief Coker stated that this research "inspired community members to get more involved, study the arts and sciences and humanities, then see how each discipline informs the other." This inspiration has led to a series of ongoing collaborations between the Lenape Tribe and other scholars throughout Delaware. The Tribe is now undertaking research on dogbane in conjunction with the Delaware Department of Natural Resources after seeing dogbane cordage on nets at the CRC. Collaborations between the Tribe and professors in Art and Art Conservation at the University of Delaware are ongoing, thanks to funding from Delaware Humanities and the Partnership for Arts \& Culture. This has resulted in a series of workshops focused on the ecology of the region as well as traditional crafts and technology. ${ }^{38}$ The author was invited to create a series of videos focused on net-making to be released during the COVID-19 pandemic, further demonstrating the resiliency of this group in the face of unpredictable challenges.

The Biggs Museum has also continued to uplift Lenape perspectives. In the fall of 2019, they exhibited a mural created by Lenape citizens and are working with the Tribe and the Division of Historical and Cultural Affairs to plan an exhibit for Native American Heritage Month 2020.

\section{Conclusion}

This project exemplifies the value of outreach and open communication with source communities in object-based decolonization and Indigenous knowledge reclamation. All museum professionals, including conservators, have a responsibility to engage source communities with the study and preservation of their material culture. This project, inspired by the nets of the last Lenape netmaker Clem Carney, succeeded in many ways. It connected the Tribe to a technology they considered lost, one that provides invaluable connections to their ancestors and their environment of the past and present. Additionally, this research connected the Lenape Tribe with their non-Native community, a necessity as they work to gain federal recognition. As a result of this project's associated outreach, people of all ages learned about the Lenape Tribe of Delaware. Participation of community members, both Native and non-Native, in this project, proved there is a strong investment and interest in the material culture and history of Indigenous peoples. It reintroduced the work of Clem Carney and his fellow netmakers to the region and demonstrated that Lenape knowledge - Lenape culture as a whole - cannot be erased by colonization and oppression. Its reclamation is possible, and this project was merely the start.

\footnotetext{
38 “Workshops,” Lenape Indian Tribe of Delaware, Accessed June 20, 2020, https://litde.net/.
} 
If you are interested in collaborating with the Lenape Tribe of Delaware, please contact the Tribal Center at 302-730-4601. If you wish to see the full technical study of the nets and associated inventory, please contact the author directly.

\section{Acknowledgements}

First and foremost, I am indebted to the Lenape Tribe of Delaware for allowing me to study part of their community's rich history and to share my findings with such a diverse and engaged audience. Thanks for this amazing privilege, and thank you to Clem Carney and many unnamed netmakers whose work was examined as part of this study. Your work has not been forgotten.

This work is a small step in decolonizing museums and the humanities as a whole, and I thank all of who are collaborating in that effort. Thank you also to the National Museum of the American Indian and the American Museum of Natural History for allowing me access to their collections. I am grateful to Dr. Jill Neitzel, Laura Mina, Dr. Vicki Cassman, Debra Hess Norris, Dr. Nancy Odegaard, and Marilen Pool for their guidance throughout this project, as well as the Delaware State Parks Department, the University of Delaware Departments of Art Conservation, Anthropology, and Art History, the Center for Historic Architecture and Design, the American Institute for Conservation, the Biggs Museum of American Art, Sophia Schmidt of Delaware First Media, the Archaeological Society of Delaware, and National Native News for their support.

\section{Bibliography}

Ashley, Clifford W. The Ashley Book of Knots. Garden City, New York: Doubleday, 1944.

Cairns, Puawai. "Decolonise or Indigenise: Moving Towards Sovereign Spaces and the Māorification of New Zealand Museology." Museum of New Zealand, Te Papa Tongarewa. February 10, 2020. Accessed June 10, 2020, https://blog.tepapa.govt.nz/2020/02/10/decolonise-or-indigenise-moving-towardssovereign-spaces-and-the-maorification-of-new-zealand-museology/.

"Core Documents: American Institute for Conservation of Historic and Artistic Works." AIC. 2015. Accessed June 25, 2020. https://www.culturalheritage.org/docs/defaultsource/administration/governance/code-of-ethics-and-guidelines-forpractice.pdf?sfvrsn=ca344aed_21.

“Decolonize This Place.” Walker Art Center. 2016. Accessed June 12, 2020. https://walkerart.org/magazine/authors/decolonize-this-place-606.

“Decolonizing Initiatives.” San Diego Museum of Man. Accessed June 12, 2020. https://www.museumofman.org/decolonizing-initiatives/.

29 DE Code $§ 106$ (2016). JUSTIA Law, Accessed June 30, 2020, https://law.justia.com/codes/delaware/2016/title-29/chapter-1/section-106/.

Dize, Ben. Personal communication. 2018. 
Garbarino, Merwyn S, and Robert F Sasso. Native American Heritage. Prospect Heights, Ill.: Waveland Press, 1996.

Harney, Elizabeth, and Ruth B Phillips, eds. Mapping Modernisms : Art, Indigeneity, Colonialism. Objects/Histories: Critical Perspectives on Art, Material Culture, and Representation. Durham: Duke University Press, 2018.

Holdgate, Charles. Netmaking. Emerson Books, 1972.

Igloliorte, Heather L, Rooms Corporation of Newfoundland and Labrador, and Rooms Provincial Art Gallery (N.L.). Sakkijâjuk : Art and Craft from Nunatsiavut. Fredericton, NB, Canada: Goose Lane Editions, 2017.

Kraft, Herbert C. The Lenape-Delaware Indian Heritage. Place of publication not identified: Lenape Books, 2001.

Kraft, Herbert C. The Lenape Indian : A Symposium. South Orange, N.J.: Archaeological Research Center, Seton Hall University, 1984.

Morton, Barbara. Down East Netting: A History and How-to of Netmaking. London: Peasoup Publishing, 1988.

"National Museum of the American Indian. History of the Collections." Smithsonian Institution. Accessed June 20, 2020. https://americanindian.si.edu/explore/collections/history.

$\mathrm{Ng}$, Wendy and AyAyQwaYakSheelth, J'net. "Decolonize and Indigenize: A Reflective Dialogue.” NAEA Museum Education. June 12, 2018. Accessed June 12, 2020. https://medium.com/viewfinder-reflecting-on-museum-education/decolonize-andindigenize-a-reflective-dialogue-3de78fa76442

Ntuli, P.P. "Indigenous Knowledge Systems and the African Renaissance." In Indigenous Knowledge and the Integration of Knowledge Systems : Towards a Philosophy of Articulation, 53-66. Place of publication not identified: New Africa Books, 2002.

Phillips, Ruth B. Museum Pieces : Toward the Indigenization of Canadian Museums. Montreal: McGill-Queen's University Press, 2011.

Schmidt, Sophia. "Lenape group and UD student travel to study traditional fishing nets." Delaware Public Media. September 14, 2018. Accessed June 20, 2020. https://www.delawarepublic.org/post/lenape-group-and-ud-student-travelstudytraditional-fishing-nets.

Schultz, Lainie. "Maintaining Aboriginal Engagement in Australian Museums: Two Models of Inclusion." Museum Management and Curatorship 29, no. 5 (2014): 412-28. 
Smith, Linda Tuhiwai. Decolonizing Methodologies : Research and Indigenous Peoples.

London: Zed Books, 1999.

Suares, B.B. and L. Guedes. "Four Waurá masks in the Indian Museum: a decolonial way to conservation practice and theory." What is the essence of conservation. ICOMOF (2014): $32-38$.

"Te Papa's work with iwi (tribes)." Museum of New Zealand Te Papa Tongarewa. Accessed June 10, 2020. https://www.tepapa.govt.nz/about/what-we-do/iwi-tribes-and-te-papa/tepapas-work-iwi-tribes\#nstp.

Weslager, C. A. The Delaware Indian Westward Migration. Wallingford, Pa.: Middle Atlantic Press, 1978.

Weslager, C. A. Delaware's Forgotten Folk: The Story of the Moors \& Nanticokes. Philadelphia: University of Pennsylvania Press, 2006 (1943).

"Workshops." Lenape Indian Tribe of Delaware. Accessed June 20, 2020. https://litde.net/. 